\title{
Formulation and stability studies of metformin hydrochloride in a controlled porosity osmotic pump system
}

\author{
Hanan M. Hashem¹, Aya R. Abdou ${ }^{1}$, Nesrin F. Taha ${ }^{1}$, Nadia M. Mursi² ${ }^{2}$ Laila H. Emara ${ }^{1 *}$ \\ ${ }^{1}$ Industrial Pharmacy Laboratory, Medicinal and Pharmaceutical Chemistry Department, Division of Pharmaceutical and Drug Industries Research, National \\ Research Centre, El Tahrir Street, Dokki, Giza 12622, Egypt. \\ ${ }^{2}$ Department of Pharmaceutics, Faculty of Pharmacy, Cairo University, Cairo 11562, Egypt.
}

\begin{tabular}{l}
\hline ARTICLE INFO \\
\hline Received on: 15/10/2019 \\
Accepted on: 27/12/2019 \\
Available online: 04/04/2020 \\
\\
\hline Key words: \\
Controlled porosity \\
osmotic pump, metformin \\
hydrochloride, biorelevant \\
media, FaSSGF, FaSSIF, \\
stability studies.
\end{tabular}

stability studies.

\begin{abstract}
This study was designed to formulate, for the first time, metformin hydrochloride ( $\mathrm{MH}, 850 \mathrm{mg} /$ tablet) as a controlled porosity osmotic pump (CPOP) system to achieve zero-order release pattern. MH core tablet was coated with cellulose acetate membrane containing PEG 400. The effect of different percentages and molecular weights of polyethylene oxide (PEO, 900K and 4M) in tablet core was studied. The United States Pharmacopeia (USP) apparatus II and phosphate buffer $\mathrm{pH} 6.8$ were used for the release studies; meanwhile, a promising formula was tested in biorelevant media. The stability of some selected formulations was carried out for 6 months, at bench and accelerated conditions. Evaluation included: MH content, Differential scanning calorimetry (DSC), Scanning electron microscopy (SEM), drug release, and kinetics. Results revealed that increasing PEO percentage within the core decreased MH release. SEM verified formation of pores in the membrane that accounts for $\mathrm{MH}$ release. Almost all stored tablets were stable for all studied parameters. MH endothermic peak maintained its position and energy of enthalpy on storage as confirmed by DSC. MH release rate from a promising formula, following zero-order release model, increased by $28 \%$ in biorelevant media compared to phosphate buffer. Subsequently, in vitro release in biorelevant media could be employed as a tool to anticipate in vivo tone of CPOP formulations.
\end{abstract}

\section{INTRODUCTION}

There has been a rising and phenomenal interest in the concept of controlled-release (CR) drug delivery systems. CR systems provide a consistent concentration of drug and thus allow the maintenance of plasma concentrations within the therapeutic range, minimizing side effects and frequency of drug administration. However, CR systems might be influenced by $\mathrm{pH}$, gastrointestinal motility, or existence of food (Banala et al., 2014).

Osmotic drug delivery systems have gained a great attention over the past decade, being one of the most upcoming

\footnotetext{
${ }^{*}$ Corresponding Author

Laila H. Emara, Industrial Pharmacy Laboratory, Medicinal and pharmaceutical chemistry Department, Division of Pharmaceutical and Drug Industries Research, National Research Centre, El Tahrir Street, Dokki, Giza 12622,Egypt.E-mail: lhhemara@yahoo.com
}

drug delivery systems (Yang et al., 2018). Accordingly, a significant increase in related articles and patents has occurred, including elementary osmotic pump (Alam et al., 2015; Emara et al., 2012; Pan et al., 2017), push-pull osmotic pump (Zeng et al., 2018; Zhang et al., 2011; Zhao et al., 2015), and controlled porosity osmotic pump (CPOP) (Emara et al., 2014; Ma et al., 2017; Phan et al., 2019; Thakkar et al., 2016). Apart from the general advantages of CR drug delivery systems, osmotic pump systems offer important characteristics including their reliability, ability to deliver the drug at $\mathrm{pH}$-independent release, zero-order release kinetics, and comparable in vitro/in vivo correlation (Patel and Parikh, 2017).

CPOP tablets are formed of an osmotic core containing the drug and an osmotic agent surrounded by a semipermeable membrane coating that includes a water-soluble pore-forming agent. On contact with aqueous media, the pore-forming agent dissolves resulting in an in situ formation of a microporous membrane that is permeable to water and dissolved solutes. Drug release from CPOP 
systems depends on the thickness of the semipermeable membrane, amount of the pore-forming agent, drug solubility, and osmotic pressure difference generated across the membrane (Emara et al., 2014; Phan et al., 2019; Thakkar et al., 2016).

Metformin hydrochloride $(\mathrm{MH})$ is considered as the firstline treatment for patients with type II diabetes according to the international guidelines. The extended release of $\mathrm{MH}$ is needed for the long-term management and control of type II diabetes mellitus. It belongs to a class of drugs known as the biguanides. $\mathrm{MH}$ has a short half-life of $1.5-4.5$ hours with an oral bioavailability of $50 \%-$ $60 \%$ and its main site of absorption is the proximal small intestine. Chemically, MH is classified according to the Biopharmaceutical Classification System as class III possessing low permeability and high solubility (Adikwu et al., 2004; Frias, 2019; Hu et al., 2006; Stepensky et al., 2001).

Few literature is available on formulating $\mathrm{MH}$ as an osmotic CR drug delivery system; i.e., elementary osmotic pump (Bharadwaj et al., 2012; Lekkala et al., 2010; Ouyang et al., 2005; Pan et al., 2017; Upadhyay and Mukerjee, 2017); asymmetric membrane technology (Banala et al., 2014); sandwiched osmotic pump (Qin et al., 2014); and inlay osmotic tablet (Patel et al., 2011). Yet, most of such osmotic systems necessitate laser drilling for their preparation; on the other hand, such step is not necessary for CPOP systems as pores are formed in situ. In addition, stomach irritation problems are reduced by the use of CPOP systems, as drug release occurs all over the osmotic pump surface rather from a single orifice (Yang et al., 2018). It is worthy to mention that the preparation of MH CPOP system with no need for orifice drilling has been reported for the first time in this article.

To establish predictive in vitro models, biorelevant media was suggested over the last years as a tool for in vitro dissolution testing. Lately, changes have been made to the media to be more mimicking for the pre and postprandial phases in the GIT (Jantratid and Dressman, 2009; Jantratid et al., 2008). The media composition has been fine-tuned referring to digestion phase in both the stomach and small intestine, since these factors can definitely influence drug dissolution rate and solubility. Consequently, the application of biorelevant dissolution test provides more predictive data in terms of in vivo drug performance (Fotaki and Vertzoni, 2010; Mann et al., 2017), thus leading to reduction in the work needed for drug development, cost, number, and size of clinical studies required (Dressman et al., 1998).

Several additives to the biorelevant media can be used to mimic the fasted and fed states of the stomach and intestine (Jantratid and Dressman, 2009; Klein, 2010). The surfactants, i.e., sodium taurocholate and lecithin (phospholipid), are the most important additives with respect to dissolution pattern of the drug. These amphiphilic molecules organize themselves onto the solidliquid interface and adjust the wetting behavior with a decline in contact angle between liquid and drug (Štukelj et al., 2019). Therefore, to relate the in vitro performance to in vivo outcomes, the surfactants utilized should be as close to in vivo conditions as much as possible (Lehto et al., 2009).

So far, only two research articles have reviewed the application of biorelevant media on the in vitro evaluation of $\mathrm{MH}$ release ( Baxevanis et al., 2018; Eaga et al., 2014). Baxevanis et al. (2018) developed an optimized protocol for $\mathrm{MH}$ for drug quantification in fed state simulated gastric fluid (FeSSGF)
(Baxevanis et al., 2018). Eaga et al. studied the dissolution studied the dissolution of $\mathrm{MH}$ modified-release tablets in fed state simulated intestinal fluid (FeSSIF). However, the complete evaluation of biorelevant media in that study was not carried out due to the cost and tedious preparation needed (Eaga et al., 2014). It is worthy to mention that in vitro evaluation of MH osmotic tablets in biorelevant media has been studied for the first time as there are no available published data regarding this topic.

$\mathrm{MH}$ osmotic pump systems were introduced in the market by 2004, as Fortamet ${ }^{\circledR}$ (available in doses of 500 and $1,000 \mathrm{mg}$ ) using the patented single-composition osmotic tablet technology (Baker, 2004; Wagstaff and Figgitt, 2004). Fortamet ${ }^{\mathbb{B}}$ manufactured by Actavis Laboratories (USA) is an expensive drug, i.e., a package of 60 tablets costs around \$2,210 and a similar package of the generic version costs $\$ 760$ in the US market. When it comes to developing countries, relative medication price is a crucial issue that should be addressed. Therefore, development of MH CR osmotic tablet comparable to the existing osmotic market product is essential to save costs and improve clinical outcomes.

The goal of this study was to prepare, for the first time, $\mathrm{MH}$ in a CPOP system. The effect of different percentages and molecular weights of PEO incorporated in the core on the release rate of $\mathrm{MH}$ was studied. Furthermore, the promising $\mathrm{MH}$ CPOP tablets were evaluated in biorelevant media, namely: fasted state simulated gastric fluid (FaSSGF) and fasted state simulated intestinal fluid (FaSSIF) in comparison with compendial medium as stated by the pharmacopeia. The stability of the proposed $\mathrm{MH}$ CPOP tablets was investigated under different storage conditions regarding in vitro $\mathrm{MH}$ release assay, kinetics, differential scanning calorimetry (DSC), and drug content.

\section{MATERIALS AND METHODS}

\section{Materials}

Pure form of MH was provided by Sigma, Cairo, Egypt, and methylparaben was bought from Sigma (St. Louis, MO, USA). Cellulose acetate (CA) (M.W.:30,000 with 39.8\% acetyl content), polyethylene oxide (PEO) M.W.:900K and 4M (Aldrich, Germany), polyethylene glycol 400 (PEG 400) (Laboratory Rasayan, India), and polyvinylpyrrolidone K-30 (PVP K-30) (M.W. 40K) (Sisco Research Laboratories, India) were used in the preparation of different CPOP tablets. Milli-Q purified water (Millipore Corp., Billerica, USA) was utilized. Acetonitrile and methanol of an HPLC grade were bought from Merck (Germany).

Potassium dihydrogen orthophosphate $\left(\mathrm{KH}_{2} \mathrm{PO}_{4}\right)$, orthophosphoric acid, sodium hydroxide (Adwic, Egypt), and sodium lauryl sulfate (El Nasr pharmaceutical chemicals, Egypt) were used to prepare the dissolution media.

Sodium chloride, pepsin (Laboratory Rasayan, India), lecithin (ROTH, Germany), and sodium taurocholate (SigmaAldrich, USA) were used to prepare the biorelevant media.

\section{Development of metformin hydrochloride CPOP}

\section{Preparation of the core tablets}

Weigh and granulate pure $\mathrm{MH}$ powder with PVP-K30 solution in alcohol, followed by sieving via sieve No. 24 (US standard sieves, Fisher-Brand). Drying of prepared granules was done in a drying oven at $50^{\circ} \mathrm{C}$ (Heraeus, Chandler,AZ) till complete 
dryness, followed by mixing with other ingredients as stated in Table 1. The mixing of all ingredients was done concurrently utilizing a polyethylene bag (Emara et al., 2014). Tablets were prepared from the different mixtures by direct compression force (Single Punch Press Tablet Machine, Stokes-Merrill Model 5117-A, Bristol, PA). A round die (13-mm diameter) was used to provide round tablets having concave surface.

\section{Drug content uniformity}

For each formulation, weigh 20 tablets and thoroughly ground followed by transfer equivalent weight of each tablet to $100 \mathrm{ml}$ volumetric flask. Distilled water was added to each flask and then mixed for 15 minutes using "temperature-controlled shaking water-bath (Lab-Line, USA)" at $37^{\circ} \mathrm{C}$. The solution was then filtered and appropriate dilutions were done to the filtrate using distilled water. The absorbance was then measured spectrophotometrically (UV-Visible spectrophotometer, Beckman, DU-650, USA) at the predetermined $\lambda_{\max } 231 \mathrm{~nm}$ for $\mathrm{MH}$ content (Pharmacopeia, 2007).

\section{Coating of the core tablets}

CA dissolved in acetone solution $(10 \% \mathrm{w} / \mathrm{v})$ was used as a coating solution. PEG 400 was incorporated in the coating solution as a hydrophilic plasticizer as well as a pore-forming agent in the following ratio (CA:PEG 400; 2.0:1.5 w/w). The membrane coating solution was sonicated for 2 hours for complete dissolution of CA. The dip-coating technique was carried out as described earlier (Altinkaya and Yenal, 2006; Banala et al., 2014; El-Zahaby et al., 2018; Emara et al., 2014). The coating was repeated a number of times till the required weight gain was achieved $(10 \% \mathrm{w} / \mathrm{w})$. To remove the residual solvent, CPOP tablets were left overnight in an oven to dry (Heraeus, Chandler, AZ). The resulting tablets were assessed for film smoothness, edge coverage, and coating uniformity by visual inspection.

\section{Release testing}

The release study of the prepared MH CPOP tablets was performed employing USP \# II (paddle dissolution apparatus)

Table 1. Composition of MH CPOP core tablets (850 mg MH/Tablet).

\begin{tabular}{lcc}
\hline \multirow{2}{*}{ Formula code* } & \multicolumn{2}{c}{ Core Composition (\% w/w) } \\
\cline { 2 - 3 } & PEO 900K & PEO 4M \\
\hline F-1 & - & 50 \\
F-2 & - & 33.3 \\
F-3 & 33.3 & - \\
F-4 & 20 & - \\
F-5 & - & 20 \\
F-6 & 5.5 & - \\
F-7 & - & 5.5 \\
F-8 & - & - \\
\hline *1\% magnesium stearate was used as a lubricant and 1\% \\
talc was used as glidant.
\end{tabular}

(AT8-Xtend, Sotax, Switzerland) in compendial phosphate buffer $\mathrm{pH} 6.8$ and biorelevant media.

\section{Quality control (QC) compendial media}

Phosphate buffer, pH 6.8 (900 ml), was employed for the QC assay, with paddle rotating at $100 \mathrm{rpm}$ (temp: $37^{\circ} \mathrm{C}$ $\left.\pm 0.5^{\circ} \mathrm{C}\right)$. Experiments were done in six replicates. Volume fractions were collected at specified time intervals, filtered $(0.45$ $\mu \mathrm{m}$ polytetrafluoroethylene filter), and then analyzed using UV/ spectrophotometer at $231 \mathrm{~nm}$.

\section{Biorelevant media}

A biorelevant, $\mathrm{pH}$-gradient media employing the paddle dissolution apparatus were used to simulate the release of $\mathrm{MH}$ from the CPOP tablets in the GIT preprandially. The biorelevant media composition is shown in Table 2 . The detailed composition and media preparation have mostly been illustrated before (Fotaki and Vertzoni, 2010; Jantratid and Dressman, 2009; Jantratid et al., 2008; Marques, 2004).

For the first 2 hours, each tablet was placed in FaSSGF, to simulate fasted state gastric conditions and to ensure sustained release properties of the formula, followed by 4 hours in FaSSIF to simulate fasted state intestinal conditions. The duration of exposure of CPOP tablets to the various fasted state simulating media was adapted from de Campo et al. (de Campo et al., 2010) and Fotaki et al. (Fotaki et al., 2005). At specified time intervals, samples were collected and assayed by a developed HPLC/UV method.

Comparison of in vitro release data using similarity factor " $f 2$ "

In vitro release profiles of the prepared formulations in different dissolution media were evaluated employing the similarity factor " $f$ " method (Moore and Flanner, 1996), according to the following equation:

$$
f_{2}=50 \times \log \left\{\left[1+\left(1 / \mathrm{n} \Sigma_{\mathrm{t}=1}{ }^{\mathrm{n}}\left(\mathrm{R}_{\mathrm{t}}-\mathrm{T}_{\mathrm{t}}\right)^{2}\right]^{-0.5} \times 100\right\}\right.
$$

Table 2. Composition of the biorelevant dissolution media simulating the preprandial conditions in the stomach and small intestine (Jantratid et al., 2008; Jantratid and Dressman, 2009; Marques, 2004).

\begin{tabular}{lcc}
\hline Medium & FaSSGF & FaSSIF \\
\hline Bile secretions & $80 \mu \mathrm{M}$ & \\
- NaTC & $20 \mu \mathrm{M}$ & $3 \mathrm{mM}$ \\
- Lecithin & & $0.75 \mathrm{mM}$ \\
Enzyme & $0.1 \mathrm{mg} / \mathrm{ml}$ & \\
- Pepsin & & - \\
Buffer & $34.2 \mathrm{mM}$ & \\
- Sodium chloride & - & $3.093 \mathrm{~g}$ \\
- NaOH (pellets) & - & $0.174 \mathrm{~g}$ \\
- NaH ${ }_{2} \mathrm{PO}_{4} \cdot \mathrm{H}_{2} \mathrm{O}$ & 1.6 & $1.977 \mathrm{~g}$ \\
$\mathrm{pH}$ & 120.7 & 6.5 \\
$\mathrm{Osmolality}(\mathrm{mOsm} / \mathrm{kg})$ & 270 \\
\hline
\end{tabular}

*Abbreviations: FaSSGF - Fast state simulated gastric fluid; FaSSIF - Fast state simulated intestinal fluid; NaTC - Sodium taurocholate; $\mathrm{NaOH}$ - Sodium hydroxide; $\mathrm{NaH}_{2} \mathrm{PO}_{4} \cdot \mathrm{H}_{2} \mathrm{O}$ - Sodium dihydrogen phosphate monohydrate. 
where, $n$ represents the number of time points, and $T_{t}$ and $R_{t}$ are the cumulative percentages release at the selected $n$ time point of the test and reference product, respectively. Release profiles are considered similar when $f_{2}$ value is in the range of 50-100 (difference $\leq 10 \%$ ) (FDA, 1997; Jantratid et al., 2009).

\section{Quantitative analysis of $\mathrm{MH}$ in biorelevant media}

\section{Chromatographic conditions}

The HPLC system consisted of Waters 600 E Delivery System Controller, Rheodyne injector P/N 7725i, and 2487 Dual k Absorbance Detector linked to Millennium 32 computer program. Symmetry C18 column was employed for the chromatographic separation $(5 \mu \mathrm{m}, 3.9 \times 150$, Waters Assoc., USA). Isocratic elution was done using a mobile phase composed of $34 \%$ acetonitrile and $66 \%$ aqueous phase. $10 \mathrm{mM}$ sodium lauryl sulfate and $10 \mathrm{mM}$ $\mathrm{KH}_{2} \mathrm{PO}_{4}$ adjusted to $\mathrm{pH} 5.2$ using dilute orthophosphoric acid were used for the preparation of aqueous phase. For each injection, the run time was 10 minutes and the flow rate was adjusted to $1 \mathrm{ml} /$ min. The column was maintained at room temperature while the detection wavelength was set at $239 \mathrm{~nm}$.

\section{Standard solutions}

Standard stock solutions of $\mathrm{MH}(1.0 \mathrm{mg} / \mathrm{ml})$ and Methyl paraben $(0.1 \mathrm{mg} / \mathrm{ml})$, as an internal standard (I.S.), were done in methanol and acetonitrile, respectively. Working standards were prepared by diluting their corresponding standard stocks with the mobile phase. Final $\mathrm{MH}$ calibration standards $(0.005-1.5 \mathrm{mg} / \mathrm{ml})$ were prepared and kept at $-20^{\circ} \mathrm{C}$ until further assay.

\section{Sample treatment}

About $0.5 \mathrm{ml}$ of biorelevant media, $50 \mu \mathrm{l}$ of calibration $\mathrm{MH}$ standards, $50 \mu \mathrm{l}$ of I.S. solution, and $50 \mu \mathrm{l}$ of $1 \mathrm{M} \mathrm{HCl}$ were vortex mixed for 30 seconds in a centrifuge tube followed by addition of $1 \mathrm{ml}$ acetonitrile and centrifugation for 10 minutes at $9,000 \mathrm{rpm}$; finally, an aliquot of $30 \mu \mathrm{l}$ of the supernatant was ready for injection.

\section{Linearity of calibration curve}

The method linearity was assessed at MH concentrations varying from 0.005 to $1.5 \mathrm{mg} / \mathrm{ml}$ using two standard calibration curves for the lower and higher concentrations (0.005-0.1 and $0.1-1.5 \mathrm{mg} / \mathrm{ml}$, respectively). $\mathrm{MH}$ concentration ranges were calculated by least squares regression analysis by charting peak area ratios of $\mathrm{MH} / \mathrm{I}$.S. versus $\mathrm{MH}$ concentration in biorelevant media.

\section{Stability studies}

The goal of the stability studies is to bring evidence on the quality of final drug product that might differ by time in a range of environmental conditions, for example, humidity and temperature. The formulations were exposed to different storage conditions as per the International Conference of Harmonization (ICH) guidelines. They were sealed in an aluminum foil pouch and stored at room temperature $\left(18^{\circ} \mathrm{C}-33^{\circ} \mathrm{C}\right)$ and $40^{\circ} \mathrm{C} \pm 0.5^{\circ} \mathrm{C}$ with $75 \%$ RH (using stability cabinet) for 6 months. Tablets were then removed and evaluated with respect to physical characteristics, DSC, drug content, drug release assay, and kinetics.

\section{Kinetic analysis of drug release data}

Data obtained from drug release studies were fitted in different mathematical equations to predict the release kinetics of $\mathrm{MH}$ from the prepared CPOP tablets. Data were then fitted to those obtained from the earlier studies (Karasulu et al., 2003; Philip and Pathak, 2006; Sood and Panchagnula, 1998):

Zero-order equation: $\mathrm{Q}_{\mathrm{t}}=\mathrm{k}_{0} . \mathrm{t}$

First-order equation: $\ln \left(100-\mathrm{Q}_{\mathrm{t}}\right)=\ln 100-\mathrm{k}_{1} . \mathrm{t}$

Higuchi release model: $\mathrm{Q}_{\mathrm{t}}=\mathrm{k}_{\mathrm{H}} \cdot \mathrm{t}^{1 / 2}$

Hixson-Crowell cube root model: $\left(100-\mathrm{Q}_{\mathrm{t}}\right)^{1 / 3}=$ $(100)^{1 / 3}-\mathrm{k}_{\mathrm{HC}} \cdot \mathrm{t}$

The standards for choosing the most suitable model were built on the best goodness of fit and the smallest sum of squared residuals (SSR) (Philip and Pathak, 2006; Sood and Panchagnula, 1998).

\section{Differential scanning calorimetry (DSC)}

Thermal behavior of pure MH, PEO 900K, PEO 4M, and freshly prepared tablets before coating was examined by DSC (SETARAM Inc., France) to explore the state of the drug and polymers in different samples. DSC analysis was done for samples stored under different storage conditions. The device was first adjusted applying the standards (mercury, indium, tin, and aluminum). Nitrogen and helium were applied as cleaning gases. The test was programmed involving heating sector from $25^{\circ} \mathrm{C}$ to $300^{\circ} \mathrm{C}$ with heating amount of $10^{\circ} \mathrm{C} / \mathrm{min}$. The samples were added in an aluminum container $(100 \mathrm{ul})$ and presented to the apparatus.

\section{Scanning electron microscopy (SEM)}

A scanning electron microscope (Quanta GEF, Netherlands) was used to inspect the surface morphology of the membrane surrounding the CPOP tablets before and after the release study. All samples were sputter-coated by gold before the SEM observations.

\section{RESULTS AND DISCUSSION}

\section{Drug content}

$\mathrm{MH}$ content for all studied formulations was within the range of $92.41 \% \pm 4.49 \%-102.24 \% \pm 1.59 \%$ which fulfilled the pharmacopoeial limits (Pharmacopoeia, 2007).

\section{Proper selection of CPOP coat composition}

PEG 400 was incorporated in the coating membrane as a leachable pore-forming material to modulate CA membrane permeability, besides it acted as a plasticizer to enhance the mechanical resistance and flexibility of the coating membrane to withstand osmotic pressure (Phan et al., 2019; Qin et al., 2014; Upadhyay and Mukerjee, 2017).

Primarily, core tablets were coated with semipermeable membrane containing different ratios of PEG 400 in CA solution. Initial results showed that incorporation of CA to PEG 400 in the following ratio $(2.0: 1.5 \mathrm{w} / \mathrm{w})$ gave the highest and most reproducible release data. This would be due to the fact that increasing the percentage of PEG 400 in the coating membrane led to more void space after leaching and subsequently, higher membrane permeability resulting in the increase of $\mathrm{MH}$ release. This outcome is in harmony with the previous work done by Emara et al. (2014). 
To choose the optimum membrane weight gain, tablets were coated with coating membrane solution with the following weight gains (i.e., $5 \%, 10 \%$, and $15 \% \mathrm{w} / \mathrm{w}$ ). It was verified that the best membrane weight gain was $10 \% \mathrm{w} / \mathrm{w}$ to keep the tablet in a rigid form and enhance its integrity throughout the release study. Further increase in membrane weight (above 10\%) led to an increase of the resistance of the membrane to water flow and a drop in the rate of water ingress into the system; hence, the tablet core could dissolve slowly and $\mathrm{MH}$ release rate would subsequently decrease (Emara et al., 2012; Li et al., 2018; Pan et al., 2017).

\section{In vitro drug release of fresh samples in compendial media}

\section{Influence of different percentage of PEO}

Swellable polymers, such as PEO, have been utilized in the fabrication of osmotic delivery of drugs. These polymers have a uniform swelling rate which assures that the drug release rate is constant. Meanwhile, the pressure formed during swelling should not lead to tear of the system (Emara et al., 2012; Patel and Parikh, 2017). In this study, PEO of two different molecular weights $(900 \mathrm{~K}$ and $4 \mathrm{M})$ was chosen as water-swellable and gelforming polymer for the formulation of $\mathrm{MH} \mathrm{CPOP}$ tablets.

Different percentages $(50 \%, 33.3 \%, 20 \%, 5.5 \%$, and $0 \%$ ) of PEO (4M and/or $900 \mathrm{~K}$ ) were incorporated in the core (c.f. Table 1) and the results are illustrated in Figure 1(a) and (b). According to the USP, a MH tablet should release between $65 \%$ and $85 \%$ of its drug content after 6 hours (Pharmacopeia, 2017). The results revealed that, in case of PEO $900 \mathrm{~K}$, the release rate of $\mathrm{MH}$ decreased as PEO percentage increased from $0 \%$ to $33.3 \%$. CPOP tablet, F-3 (33.3\%, PEO 900K), possessed the lowest release rate compared to F-4, F-6, and F-8 containing 20\%, 5\%, and $0 \%$ of PEO $900 \mathrm{~K}$, respectively (Fig. 1a). Due to core volume restriction, $\mathrm{PEO}$ with high percentage might form a highly compact and complex net structure with narrow channels. This net structure would slow down $\mathrm{MH}$ diffusion rate and prolong the release process consequently. In addition, competition between $\mathrm{MH}$ and PEO on the same amount of water penetrating into the tablet will eventually lead to decrease $\mathrm{MH}$ release.

Figure 1(b) shows similar observation on using PEO $4 \mathrm{M}$, where increasing the percentage of PEO within the core led to a simultaneous decrease in drug release. Similar observations were reported by Kumar et al. (2009) during the development and evaluation of an elementary osmotic pump of tramadol hydrochloride, where increasing the concentration of PEO $300 \mathrm{~K}$ inside the core led to decline in drug release rate (Kumar et al., 2009).

It is always a great challenge for researchers to use the least possible amount of excipients and yet provide a desired sustained-release effect of model drugs and this is what we craved for in this study. The previous studies fabricated $\mathrm{MH}$ in different osmotic systems, either with an osmotic agent (Bharadwaj et al., 2012; Banala et al., 2014; Lekkala et al., 2010; Upadhyay and Mukerjee, 2017) or with a combination of osmotic agent and swelling polymer (Patel et al., 2011). However, in our study, we successfully formulated $\mathrm{MH}$ in a CPOP system without addition of an osmotic agent or swelling polymer (F-8) and the highest release rate was achieved $\left(\mathrm{Q}_{6 \mathrm{~h}}\right.$ value of $\left.66.44 \%\right)$, so $\mathrm{MH}$ can be formulated solely in an osmotic system and would be expected to provide sufficient osmotic pressure difference within the system to sustain the release for several hours.

\section{Influence of different molecular weights of PEO}

Figure 2 reveals that the effect of different molecular weights of $\mathrm{PEO}$ was only pronounced on using a high percentage of polymer $(\geq 33 \%)$, whereas on using lower percentages of PEO $(\leq 20 \%)$, such difference did not show declared effect on $\mathrm{MH}$ release pattern. For MH CPOP tablets containing 33.3\% PEO, the cumulative amount of $\mathrm{MH}$ released after 6 hours $\left(\mathrm{Q}_{6 \mathrm{~h}}\right)$ was $51 \%$ and $37 \%$ for PEO $4 \mathrm{M}(\mathrm{F}-2)$ and PEO $900 \mathrm{~K}$ (F-3), respectively (Figure 2). The calculated $f_{2}$ value was 47 which proposed dissimilar release profiles. On the other hand, for MH CPOP tablets containing $20 \%$ and $5.5 \%$ PEO, differences in polymer molecular weights $(900 \mathrm{~K}$ and $4 \mathrm{M})$ did not affect the release pattern in a significant way $\left(f_{2}\right.$ values were $\left.\geq 50\right)$.

It is worthy to mention that, CPOP tablets containing high polymer percentage ( $\geq 20 \%)$ (i.e., F-1 to F-5), high drug release was observed with increasing PEO molecular weight. At the end of the release study, few tiny cracks were visually observed on the membrane, which might be due to high pressure generated within the system, leading to irreproducible in vitro release results (as detected with high standard deviation; Figure 1(b) and 2).

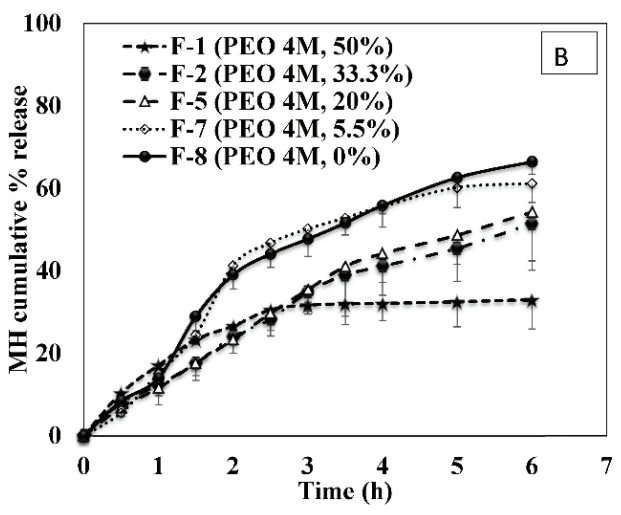

Figure 1. Effect of percentage of (a) PEO $900 \mathrm{~K}$ and (b) PEO $4 \mathrm{M}$ on the release profile of MH from CPOP tablets (Mean \pm S.D., $n=6$ ). 


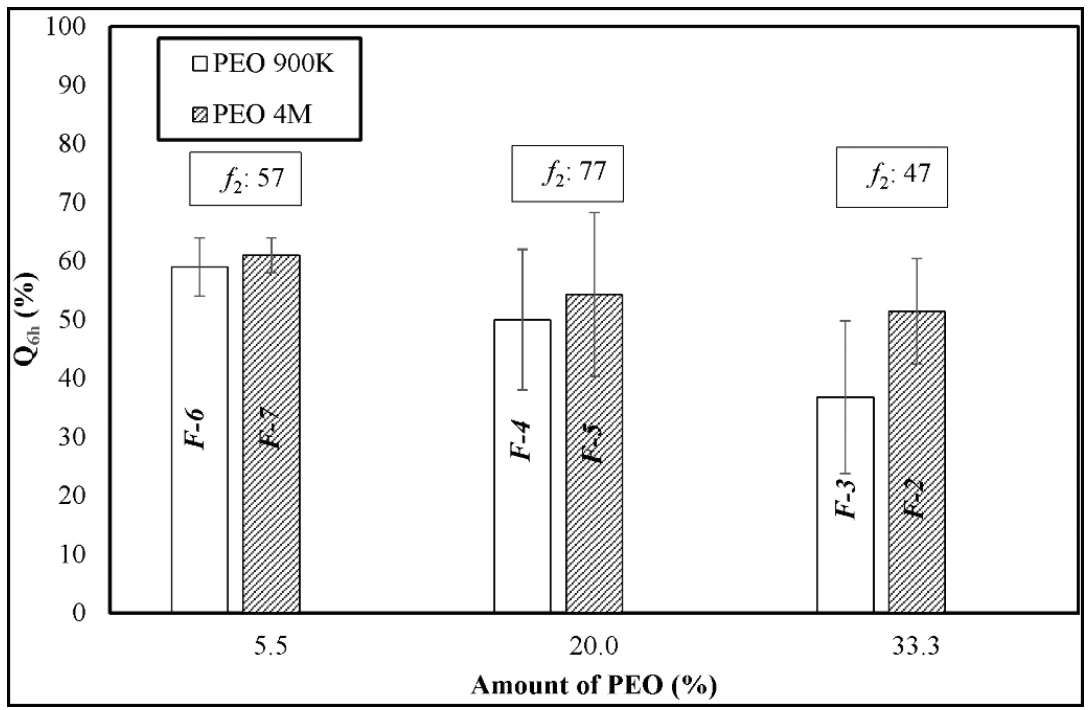

Figure 2. Bar chart showing $\mathrm{Q}_{6 \mathrm{~h}}$ of $\mathrm{MH}$ with $\mathrm{PEO}$ of different molecular weights at different polymer percentage (Mean \pm S.D., $n=6$ ).

Meanwhile, in Figure 2, CPOP tablets containing low polymer percentage (5.5\%) (i.e., F-6 and F-7), slightly higher drug release was observed with increasing PEO molecular weight. Still, these two formulations successfully maintained their membrane integrity during the release study and provided the desired sustained release of $\mathrm{MH}$ over a 6 hours release period. The same applied for F-8 which did not contain PEO in its tablet core. Their corresponding release data were reproducible with low standard deviation (Figure: $1 \mathrm{a}$ and $\mathrm{b}$ ).

In general, swelling osmotic device undergoes physical changes throughout release testing which are of significance in explaining drug release (Keraliya et al., 2012). Therefore, formulations (F-6, F-7, and F-8) were selected for further investigation regarding their stability on storage.

Lekkala et al. and Zhao et al. previously studied the release profile of Fortamet ${ }^{\circledR}$ and stated that the release rate of Fortamet ${ }^{\circledR}$ was $56 \%$ after 6 hours in phosphate buffer pH 6.8 (Lekkala et al., 2010; Zhao et al., 2012). Those results are comparable with the cumulative release percentage of the proposed MH CPOP tablets in the present study. The $\mathrm{Q}_{6 \mathrm{~h}}$ values for our formulations were $61.8 \%, 63.20 \%$, and $66.44 \%$ for F-6, F-7, and F-8, respectively.

\section{Stability studies}

Visual inspection of some selected formulations (F-6, F-7, and F-8) after storage at different conditions for 6 months, showed no changes in color/appearance of tablets.

\section{Drug content}

Results demonstrated that, for all stored samples, MH content varied between $90.29 \% \pm 1.59 \%$ and $104.64 \% \pm$ $4.74 \%$, which acted in accordance with the acceptable limits of pharmacopoeia (Pharmacopoeia, 2007).

\section{In vitro release study of stored samples}

Figure 3(a)-(c) illustrates the in vitro release profiles of MH from stored samples (F-6, F-7, and F-8), whereas Figure 4 illustrates the $f_{2}$ values, comparing their release profiles. It is obvious that almost all tested MH CPOP tablets gave similar release profiles after storage for 6 months either on bench $\left(18^{\circ} \mathrm{C}-33^{\circ} \mathrm{C}\right)$ or at accelerated conditions $\left(40^{\circ} \mathrm{C} / 75 \% \mathrm{RH}\right)$ as proved by the similarity factor values $\left(f_{2} \geq 50\right)$. Only formula $\mathrm{F}-7$, stored under accelerated conditions $\left(40^{\circ} \mathrm{C} / 75 \% \mathrm{RH}\right)$, gave lower $\mathrm{MH}$ release rate compared to the fresh tablets $\left(f_{2}=45\right)$.

The results of release studies after 6 months storage under the most drastic conditions $\left(40^{\circ} \mathrm{C} / 75 \% \mathrm{RH}\right)$ for F-6, F-7, and F- 8 gave the following $f_{2}$ values: 81,45 , and 50 , respectively, which clarified that F-6 was the best formula that tolerated these storage conditions. Accordingly, F-6 was the formula of choice for the upcoming biorelevant dissolution test.

\section{Kinetics of drug release data}

Table 3 demonstrates the regression analysis of $\mathrm{MH}$ release data from the prepared MH CPOP tablet formulations, before and after storage, showing the suggested kinetic models with the smallest SSR (for full details; refer to Supplementary Figures). The drug release pattern from fresh MH CPOP tablets followed: (i) zeroorder model (F-6 and F-8), i.e., MH release rate, was independent of its concentration (Philip and Pathak, 2006) and (ii) Hixson and Crowell Cube-Root model (F-7) clarified that the release of the drug is depended on the change in diameter and surface area of the tablets with time which is a typical case of systems that dissolute or erode over time (Philip and Pathak, 2006). The suggested kinetic release models for the tested formulations on storage were the same compared with their corresponding fresh samples for the three selected MH CPOP formulations (c.f. Table 3).

\section{DSC studies}

Figure 5 displays the thermal analysis of the selected freshly prepared formulations and their DSC thermograms after storage. The DSC thermogram of pure $\mathrm{MH}$ revealed a typical melting endotherm at $230^{\circ} \mathrm{C}$ together with a normalized energy of $251.18 \mathrm{~J} / \mathrm{g}$. No change in the melting endotherm of $\mathrm{MH}$ was recognized for the prepared fresh tablets (F-6, F-7, and F-8); therefore, it was inferred that there was no interaction between $\mathrm{MH}$ and $\mathrm{PEO}$ within the tablets. 


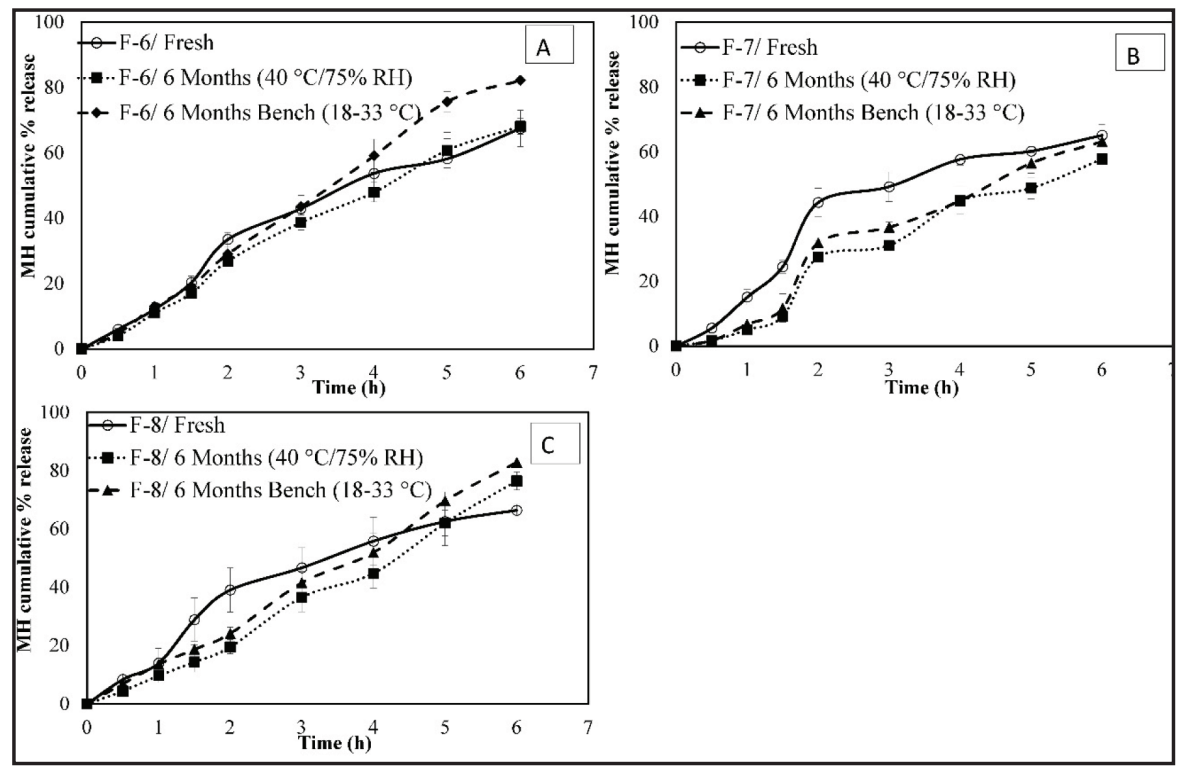

Figure 3. Effect of different storage conditions on the release profile of MH CPOP tablets. (a): F-6 (PEO 900K, 5.5\%); (b): F-7 (PEO 4M, 5.5\%); and (c): F8 (PEO, 0\%) (Mean \pm S.D., $n=6$ ).

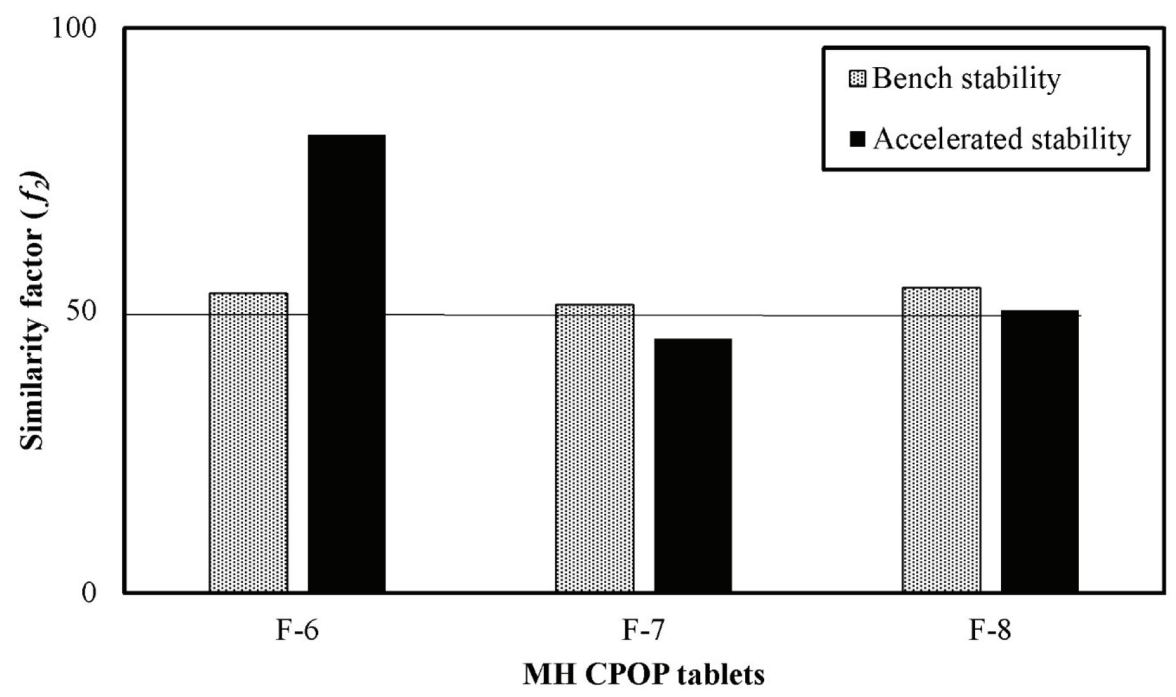

Figure 4. Similarity factor $\left(f_{2}\right)$ values comparing the release profiles of $\mathrm{MH}$ from selected $\mathrm{CPOP}$ tablets before and after storage under accelerated $\left(40^{\circ} \mathrm{C} / 75 \% \mathrm{RH}\right)$ and bench conditions $\left(18^{\circ} \mathrm{C}-33^{\circ} \mathrm{C}\right)$ for 6 months.

At different storage conditions of temperature and humidity, all stored samples showed almost the same DSC thermograms as compared with their corresponding fresh samples, where $\mathrm{MH}$ endothermic peak maintained its position and energy of enthalpy for all stored formulations (Fig. 5).

\section{Quantitative analysis of MH in biorelevant media by HPLC}

The optimized HPLC/UV method developed for the assay of $\mathrm{MH}$ in biorelevant media showed reliable, linear results within the concentration range of $0.005-1.5 \mathrm{mg} / \mathrm{ml}$. The limit of detection was $0.002 \mathrm{mg} / \mathrm{ml}$ while the limit of quantification was $0.005 \mathrm{mg} / \mathrm{ml}$ and the mean recovery of $97.0 \% \pm 1.6 \%$ was noted. The accuracy and precision of the assay were less than $5 \%$.

\section{Release profile of MH osmotic tablets in biorelevant media}

Biorelevant dissolution media have been updated to simulate better the characteristics and composition of proximal human GIT, i.e., FaSSGF and FeSSIF (Dressman et al., 2007; Jantratid and Dressman, 2009; Jantratid et al., 2008). The media composition, as presented in Table 2, reflected the physiological changes over the GIT in the preprandial state. Necessary parameters affecting drug dissolution and solubility including: 1) the presence of lipolytic products and enzymes; 2) the level of bile secretions; and 3) the buffer capacity, $\mathrm{pH}$, and osmolality were all considered (Jantratid et al., 2009).

Figure 6 shows the results of the effect of such media on the release pattern of MH CPOP tablets. F-6 was 
Table 3. Regression analysis, SSR, and coefficient of determination " ${ }^{2}$ " values for the different kinetic models for the release data of some selected formulations.

\begin{tabular}{|c|c|c|c|c|c|c|c|c|c|c|}
\hline \multirow{3}{*}{ Release Model } & \multicolumn{10}{|c|}{ CPOP Tablets } \\
\hline & \multicolumn{4}{|c|}{ F-6 } & \multicolumn{3}{|c|}{ F-7 } & \multicolumn{3}{|c|}{ F-8 } \\
\hline & & Fresh & $\begin{array}{l}6 \text { months } \\
\text { bench }\end{array}$ & $\begin{array}{l}6 \text { months } \\
\text { accelerated }\end{array}$ & Fresh & $\begin{array}{l}6 \text { months } \\
\text { bench }\end{array}$ & $\begin{array}{l}6 \text { months } \\
\text { accelerated }\end{array}$ & Fresh & $\begin{array}{l}6 \text { months } \\
\text { bench }\end{array}$ & $\begin{array}{l}6 \text { months } \\
\text { accelerated }\end{array}$ \\
\hline \multirow[t]{3}{*}{ Zero-order } & SSR & $\underline{42.34}$ & $\underline{73.9}$ & $\underline{22.17}$ & 619.88 & 191.75 & 204.29 & $\underline{199.8}$ & $\underline{27.29}$ & $\underline{78.1}$ \\
\hline & $\mathbf{r}^{2}$ & 0.99 & 1 & 1 & 0.9 & 0.95 & 0.94 & 0.98 & 0.99 & 0.99 \\
\hline & $\mathbf{k}\left(\mathbf{m o l} . \mathrm{l}^{-1} \cdot \mathrm{h}^{-1}\right)$ & 12.4 & 15.69 & 12.51 & 12.35 & 12.3 & 11.28 & 12.1 & 13.81 & 12.75 \\
\hline \multirow[t]{3}{*}{ First-order } & SSR & 46.45 & 181.49 & 39.04 & 176.34 & 134.05 & 99.11 & 210.63 & 143.82 & 105.66 \\
\hline & $\mathbf{r}^{2}$ & 0.98 & 0.96 & 0.99 & 0.94 & 0.95 & 0.96 & 0.97 & 0.96 & 0.96 \\
\hline & $\mathbf{k}\left(\mathbf{h}^{-1}\right)$ & 0.19 & 0.29 & 0.2 & 0.2 & 0.18 & 0.16 & 0.2 & 0.24 & 0.2 \\
\hline \multirow[t]{3}{*}{ Higuchi Square Root of Time } & SSR & 17592.6 & 31668 & 18601.75 & 15392.4 & 21356 & 19105.55 & 11073.4 & 21514 & 21988.45 \\
\hline & $\mathbf{r}^{2}$ & 0.98 & 0.98 & 0.99 & 0.96 & 0.96 & 0.95 & 0.97 & 0.96 & 0.95 \\
\hline & $\mathrm{k}\left(\mathrm{mol} . \mathrm{l}^{-1} \cdot \mathrm{h}^{-1 / 2}\right)$ & 37.14 & 46.49 & 37.49 & 37.99 & 37.13 & 33.99 & 36.8 & 40.72 & 37.53 \\
\hline \multirow[t]{3}{*}{ Hixson-Crowell Cube-Root } & SSR & 57.04 & 78.68 & 27.46 & $\underline{84.06}$ & $\underline{106.96}$ & $\underline{98.72}$ & 202.32 & 75.71 & 83.08 \\
\hline & $\mathbf{r}^{2}$ & 0.98 & 0.98 & 0.98 & 0.97 & 0.96 & 0.96 & 0.98 & 0.98 & 0.97 \\
\hline & $\mathbf{k}\left(\mathbf{m o l}^{1 / 3} \cdot \mathbf{l}^{-1 / 3} \cdot \mathbf{h}^{-1}\right)$ & 0.25 & 0.36 & 0.26 & 0.27 & 0.24 & 0.22 & 0.26 & 0.3 & 0.26 \\
\hline \multicolumn{3}{|c|}{ Suggested Release Model (Smallest SSR) } & Zero-order & & \multicolumn{3}{|c|}{ Hixson and Crowell Cube-Root } & \multicolumn{3}{|c|}{ Zero-order } \\
\hline
\end{tabular}

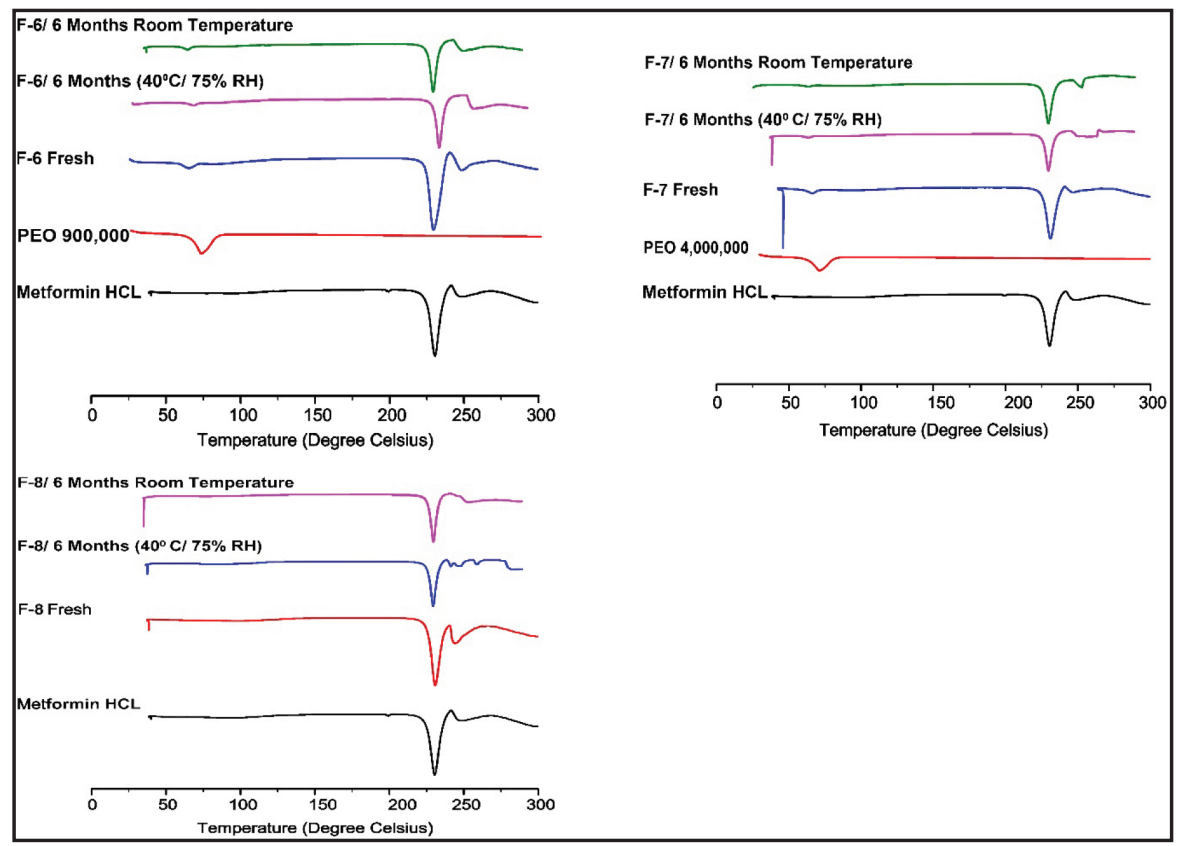

Figure 5. DSC thermograms of $\mathrm{MH}$ and $\mathrm{PEO}$ in pure forms and the selected formulations at zero time and after storage.

selected as the formulation of choice for such study based on its in vitro release results and their stability after storage under accelerated conditions (c.f. Fig. 4). It is obvious from Figure 6 that the release rate of F- 6 increased on using biorelevant media compared to the release rate in compendial dissolution medium (phosphate buffer $\mathrm{pH} 6.8$ ). $\mathrm{Q}_{6 \mathrm{~h}}$ values were $90 \%$ and $61.8 \%$ in biorelevant and compendial media, respectively. Data were expressed as the mean \pm standard deviation, and the $\mathrm{Q}_{6 \mathrm{~h}}$ values were deemed to be statistically significant $(p$-value $=0.004923)$. Although osmotic drug delivery systems have been intended to be potent against the effect of GIT conditions both in vitro and in vivo, certain differences in $\mathrm{MH}$ release pattern were observed depending on the media used. A possible explanation for the observed increase in $\mathrm{MH}$ release rate in biorelevant media could be attributed to the high osmolality of FaSSGF (120.7 $\mathrm{mOsmol} / \mathrm{kg}$ ) and FaSSIF (270 mOsmol/ $\mathrm{kg}$ ). Consequently, a 


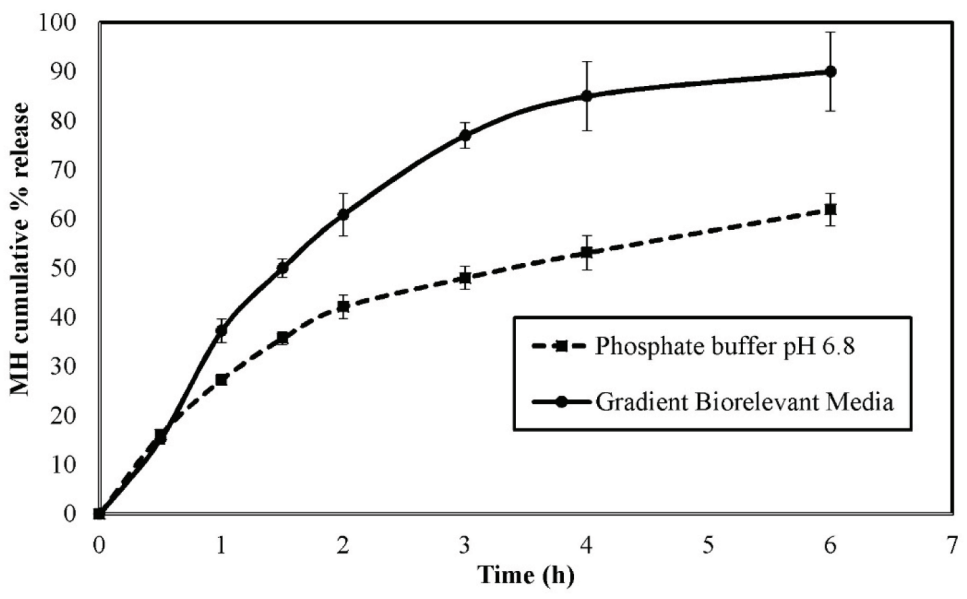

Figure 6. Comparison of the release profiles of MH CPOP tablet (F-6) in phosphate buffer (pH 6.8) and gradient biorelevant media (mean \pm S.D., $n=6$ ).

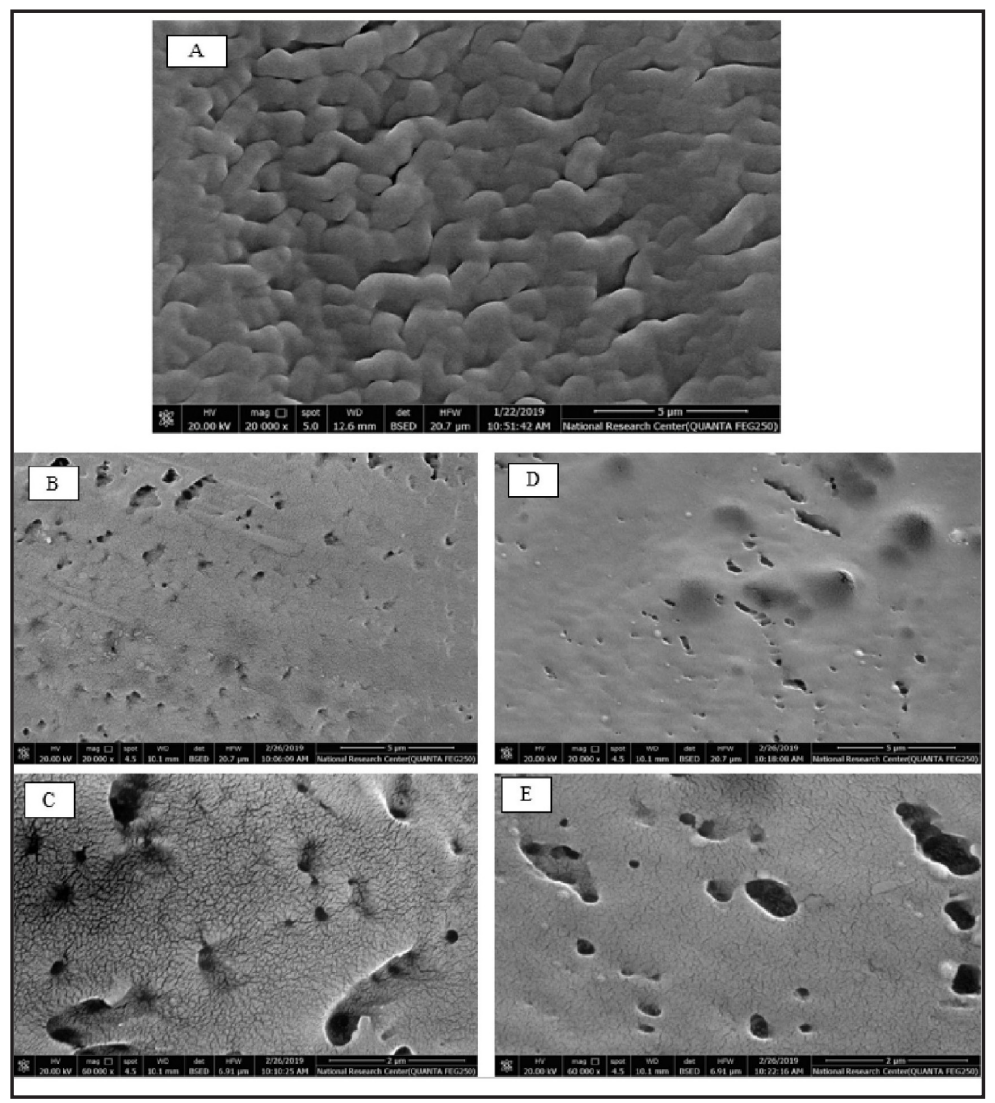

Figure 7. SEM images of top surface of semipermeable membrane of the prepared $\mathrm{MH}$ CPOP tablet before release (a); after release in phosphate buffer (pH 6.8) at X20000 and X60000 (b, c), respectively; and after release in biorelevant media at X20000 and X60000 $(\mathrm{d}, \mathrm{e})$, respectively.

high difference in osmotic pressure was created, which might cause an increase in the permeability of the coat membrane and thus, an increase in MH release rate (Bibi et al., 2015).

\section{Scanning electron microscopy}

SEM images of the semipermeable membrane of MH CPOP tablets (F-6) before and after release study employing different dissolution media are shown in Figure 7(a)-(e). Figure 7(a) shows the membrane structure before release studies, the CA membrane was folded, and the coat seemed to be free of defects and nonporous.

Figure 7(b) and (c) pictures the porous membrane after release in phosphate buffer ( $\mathrm{pH}$ 6.8) using two different magnification scales. The micrographs reflected a tight structure 
with few wrinkles on the surface, and the formation of pores was clearly seen on the surface of membrane, possibly due to the dissolution of PEG 400 on contact of the membrane with release medium.

Meanwhile, Figure 7(d) and (e) shows the surface of the porous membrane after release in gradient biorelevant media using the same two magnification scales. SEM images clarified that the size of pores relatively increased in biorelevant media compared to phosphate buffer ( $\mathrm{pH}$ 6.8) (Fig. $7 \mathrm{~b}$ and c). The observed wrinkled morphology in the case of phosphate buffer ( $\mathrm{pH} 6.8$ ) was changed to smooth surface in biorelevant media (Fig. 7c and e). These observations reinforce the results obtained from the release studies in both media, where the $\mathrm{Q}_{6 \mathrm{~h}}$ of $\mathrm{MH}$ increased by $28 \%$ in biorelevant media compared to phosphate buffer $(\mathrm{pH} 6.8)$.

\section{CONCLUSION}

It is worthy to mention that this is the first study to formulate $\mathrm{MH}$ as CPOP system and to investigate its release pattern in fast state biorelevant media (FaSSGF and FaSSIF). The merits of the proposed CPOP tablets include: 1) ability to deliver $\mathrm{MH}$ at zero-order release kinetics, 2) capability to rule out sophisticated and expensive laser drill technology, 3) formulation of stable tablets without using osmotic agents, 4) utilization of the minimum percentage of swelling polymer, 5) reduction of the manufacturing costs of the osmotic pump system, and 6) provision of the needed potentials for large industrial scale production. The study highlighted that the release rate of $\mathrm{MH}$ differed distinctly between the compendial dissolution medium and biorelevant media. The promising step forward is to carry out further in vivo investigation to support our findings related to biorelevant media and provide full $I V I V$ correlation.

\section{CONFLICT OF INTEREST}

Authors declare that there are no conflicts of interest.

\section{REFERENCES}

Adikwu MU, Yoshikawa Y, Takada K. Pharmacodynamicpharmacokinetic profiles of metformin hydrochloride from a mucoadhesive formulation of a polysaccharide with antidiabetic property in streptozotocininduced diabetic rat models. Biomaterials 2004; 25(15):3041-8.

Alam N, Beg S, Rizwan M, Ahmad A, Ahmad FJ, Ali A, Aqil M. Mucoadhesive elementary osmotic pump tablets of trimetazidine for controlled drug delivery and reduced variability in oral bioavailability. Drug Dev Ind Pharm 2015; 41(4):692-702.

Altinkaya SA, Yenal $\mathrm{H}$. In vitro drug release rates from asymmetric-membrane tablet coatings: Prediction of phase-inversion dynamics. Biochem Eng J 2006; 28(2):131-9.

Baker DE. New drugs approved by the FDA; New dosage forms and indications; Agents pending FDA approval; Significant labeling changes related to safety. Hosp Pharm 2004; 39(8):786-801.

Banala VT, Srinivasan B, Rajamanickam D, Veerbadraiah BB, Varadharajan M. Development of asymmetric membrane capsules of metformin hydrochloride for oral osmotic controlled drug delivery. Asian J Pharm 2014; 8(1).

Baxevanis F, Kuiper J, Fotaki N. Strategic drug analysis in fedstate gastric biorelevant media based on drug physicochemical properties. Eur J Pharm Biopharm 2018; 127:326-41.

Bharadwaj P, Upaddhyay P, Agarwal V, Chaurasia D, Chaurasia $\mathrm{H}$, Singh R. Development and characterization of elementary osmotic pump tablets for simultaneous release of metformin and glipizide. Indian Drugs 2012; 49(11):19-29.
Bibi HA, Di Cagno M, Holm R, Bauer-Brandl A. Permeapad ${ }^{\mathrm{TM}}$ for investigation of passive drug permeability: the effect of surfactants, cosolvents and simulated intestinal fluids (FaSSIF and FeSSIF). Int J Pharm 2015; 493(1-2):192-7.

British Pharmacopoeia. Index for Windows v1.16c Win32 Release Build, System Simulation Ltd. 1994-2006 (C.D.) London: The Stationary Office. British Pharmacopoeia Commission, 2007.

de Campo DR, Klein S, Zolle T, Vieri NR, Barro FAP, Meure EC, Coelho EC, Marchiorett MA, Pedrazzoli J. Evaluation of pantoprazole formulations in different dissolution apparatus using biorelevant medium. Arzneimittelforschung 2010; 60(01):42-7.

Dressman J, Schamp K, Beltz K, Alsenz J. Characterizing release from lipid-based formulations. In: Oral Lipid-Based Formulations, CRC Press, Boca Raton, FL, pp. 263-78, 2007.

Dressman JB, Amidon GL, Reppas C, Shah VP. Dissolution testing as a prognostic tool for oral drug absorption: immediate release dosage forms. Pharm Res 1998; 15(1):11-22.

Eaga C, Mantri S, Malayandi R, Kondamudi PK, Chakraborty S, Raju S, Aggarwal D. Establishing postprandial bio-equivalency and IVIVC for generic metformin sustained release small sized tablets. J Pharm Invest 2014; 44(3):197-204.

El-Zahaby SA, AbouGhaly MH, Abdelbary GA, El-Gazayerly O. Zero-order release and bioavailability enhancement of poorly water soluble Vinpocetine from self-nanoemulsifying osmotic pump tablet. Pharm Dev Technol 2018; 23(9):900-10.

Emara LH, Taha NF, Badr RM, Mursi NM. Development of an osmotic pump system for controlled delivery of diclofenac sodium. Drug Discoveries Ther 2012; 6(5):269-77.

Emara LH, Taha NF, El-Ashmawy AA, Raslan HM, Mursi NM Controlled porosity osmotic pump system for the delivery of diclofenac sodium: in-vitro and in-vivo evaluation. Pharm Dev Technol 2014; 19(6):681-91.

Food and Drug Administration (FDA). Guidance for industry: dissolution testing of immediate-release solid oral dosage forms. Food and Drug Administration, Center for Drug Evaluation and Research (CDER), Rockville, MD. 1997.

Fotaki N, Symillides M, Reppas C. In vitro versus canine data for predicting input profiles of isosorbide-5-mononitrate from oral extended release products on a confidence interval basis. Eur J Pharm Sci 2005; 24(1):115-22.

Fotaki N, Vertzoni M. Biorelevant dissolution methods and their applications in in vitro-in vivo correlations for oral formulations. Open Drug Del J 2010; 4(1).

Frias JP. Fixed-dose combination of ertugliflozin and metformin hydrochloride for the treatment of type 2 diabetes. Expert Rev Endocrinol Metab 2019; 14(2), 75-83.

Hu L-D, Liu Y, Tang X, Zhang Q. Preparation and in vitro/in vivo evaluation of sustained-release metformin hydrochloride pellets. Eur J Pharm Biopharm 2006; 64(2):185-92.

Jantratid E, De Maio V, Ronda E, Mattavelli V, Vertzoni M, Dressman J. Application of biorelevant dissolution tests to the prediction of in vivo performance of diclofenac sodium from an oral modified-release pellet dosage form. Eur J Pharm Sci 2009; 37(3-4):434-41.

Jantratid E, Dressman J. Biorelevant dissolution media simulating the proximal human gastrointestinal tract: an update. Dissolution Technol 2009; 16(3):21-5.

Jantratid E, Janssen N, Reppas C, Dressman J. Dissolution media simulating conditions in the proximal human gastrointestinal tract: an update. Pharm Res 2008; 25(7):1663.

Karasulu E, Karasulu HY, Ertan G, Kirilmaz L, Güneri T Extended release lipophilic indomethacin microspheres: formulation factors and mathematical equations fitted drug release rates. Eur J Pharm Sci 2003; 19(2-3):99-104.

Keraliya RA, Patel C, Patel P, Keraliya V, Soni TG, Patel RC, Patel M. Osmotic drug delivery system as a part of modified release dosage 
form. ISRN Pharm 2012; 2012

Klein $\mathrm{S}$. The use of biorelevant dissolution media to forecast the in vivo performance of a drug. AAPS J 2010; 12(3):397-406.

Kumar P, Singh S, Mishra B. Development and evaluation of elementary osmotic pump of highly water soluble drug: tramadol hydrochloride. Curr Drug Delivery 2009; 6(1):130-9.

Lehto P, Aaltonen J, Tenho M, Rantanen J, Hirvonen J, Tanninen VP, Peltonen L. Solvent-mediated solid phase transformations of carbamazepine: effects of simulated intestinal fluid and fasted state simulated intestinal fluid. J Pharm Sci 2009; 98(3):985-96.

Lekkala VK, Aminnabavi NB, Bhavanam PR, Rama Therdana Rao P, Siva Ramakrishna G, Anjireddy K. Formualtion and optimization of extended release of metformin hydrochloride tablets by osmotic technology. Int J Pharm Technol 2010; 1(2):163-82.

Li Y, Pan H, Duan H, Chen J, Zhu Z, Fan J, Li P, Yang X, Pan W. Double-layered osmotic pump controlled release tablets of actarit: In vitro and in vivo evaluation. Asian J Pharm Sci 2018; 14(3):340-8.

Ma C, Huang Z, Zhu Y, Chen X, Singh V, Huang Y, Pan X, Wu C. Production and in vitro evaluation of a lamotrigine extended release tablet based on a controlled-porosity osmotic pump system. Die Pharm Int J Pharm Sci 2017; 72(9):511-7.

Mann J, Dressman J, Rosenblatt K, Ashworth L, Muenster U, Frank K, Hutchins P, Williams J, Klumpp L, Wielockx K. Validation of dissolution testing with biorelevant media: an OrBiTo study. Mol Pharmaceutics 2017; 14(12):4192-201.

Marques M. Dissolution media simulating fasted and fed states. Dissolution Technol 2004; 11(2):16-9.

Moore J, Flanner H. Mathematical comparison of dissolution profiles. Pharmaceutical Technol 1996; 20(6):64-74.

Ouyang D, Nie S, Li W, Guo H, Liu H, Pan W. Design and evaluation of compound metformin/glipizide elementary osmotic pump tablets. J Pharm Pharmacol 2005; 57(7):817-20.

Pan H, Jing H, Yang X, Pan W, Chen T. Synchronized and controlled release of metformin hydrochloride/glipizide from elementary osmotic delivery. Drug Dev Ind Pharm 2017; 43(5):780-88.

Patel HJ, Parikh VP. An overview of osmotic drug delivery system: an update review. Int J Bioassays 2017; 6(7):5426-36.

Patel R, Patel G, Patel H, Patel M. Inlay osmotic pump tablets containing metformin and glipizide. Drug Dev Ind Pharm 2011; 37(10):1244-52.

Phan HV, Vu TTG, Doan CS. Formulation of controlled porosity osmotic pump tablets containing venlafaxine hydrochloride. Pharm Sci Asia 2019; 46(2):98-107.

Philip AK, Pathak K. Osmotic flow through asymmetric membrane: a means for controlled delivery of drugs with varying solubility. AAPS Pharm Sci Tech 2006; 7(3):E1-E11.

Qin C, He W, Zhu C, Wu M, Jin Z, Zhang Q, Wang G, Yin L. Controlled release of metformin hydrochloride and repaglinide from sandwiched osmotic pump tablet. Int J Pharm 2014; 466(1-2):276-85.
Sood A, Panchagnula R. Drug release evaluation of diltiazem CR preparations. Int J Pharm 1998; 175(1):95-107.

Stepensky D, Friedman M, Srour W, Raz I, Hoffman A. Preclinical evaluation of pharmacokinetic-pharmacodynamic rationale for oral CR metformin formulation. J Controlled Release 2001; 71(1):107-15.

Štukelj J, Svanbäck S, Kristl J, Strachan CJ, Yliruusi J. Imagebased investigation: biorelevant solubility of $\alpha$ and $\gamma$ indomethacin. Anal Chemi 2019; 91:3997-4003.

Thakkar HP, Pancholi N, Patel CV. Development and evaluation of a once-daily controlled porosity osmotic pump of tapentadol hydrochloride. AAPS Pharm Sci Tech 2016; 17(5):1248-60.

Upadhyay PK, Mukerjee A. Development and characterization of osmotic pump tablets bearing antidiabetic drugs. World J Pharm Res 2017; 6(13):350-60.

USP Pharmacopeia. The United States Pharmacopeia 30: The National Formulary 25. 30 ed. The United States Pharmacopeial Convention, Inc., Rockville, MD, 2007.

USP Pharmacopeia. United States Pharmacopeia (USP). 40a ed. The United States Pharmacopeial Convention, Inc., Rockville, MD, 2017.

Wagstaff AJ, Figgitt DP. Extended-Release Metformin Hydrochloride. Treat Endocrinol 2004; 3(5):327-32.

Yang Q, Ma Y, Shi K, Yang G, Zhu J. Electrostatic coated controlled porosity osmotic pump with ultrafine powders. Powder Technol 2018; 333:71-7.

Zeng Y, Zhu L, Guo Z, Liu H, Fen W, Liao S, Duan T. Preparation and formula optimization of diphenidol hydrochloride push-pull osmotic pump tablets. J China Pharmacist 2018; 21(10):1750-5.

Zhang Z-H, Dong H-Y, Peng B, Liu H-F, Li C-L, Liang M. Design of an expert system for the development and formulation of pushpull osmotic pump tablets containing poorly water-soluble drugs. Int $J$ Pharm 2011; 410(1-2):41-7.

Zhao L, Wei Y, Mei Y, Yang L, You Y, Yang X, Jiang Y. Preparation and in vitro drug release evaluation of once-daily metformin hydrochloride sustained-release tablets. Pharmacol Pharm 2012; 3(4):468-73.

Zhao Z, Wu C, Zhao Y, Hao Y, Liu Y, Zhao W. Development of an oral push-pull osmotic pump of fenofibrate-loaded mesoporous silica nanoparticles. Int J Nanomed 2015; 10:1691-701.

How to cite this article:

Hashem HM, Abdou AR, Taha NF, Mursi NM, Emara LH. Formulation and stability studies of metformin hydrochloride in a controlled porosity osmotic pump system. J Appl Pharm Sci, 2020; 10(04):100-112. 


\section{SUPPLEMENTARY FIGURES}
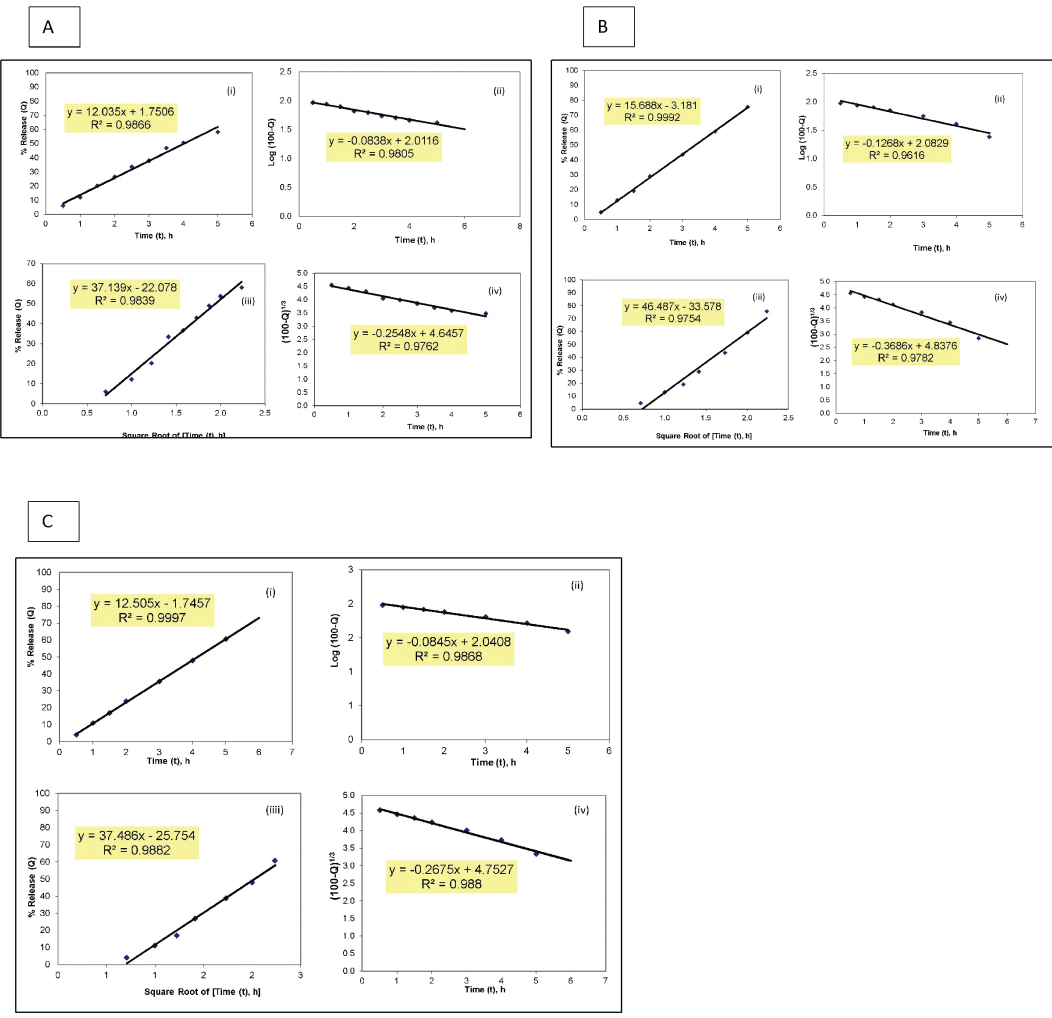

Supplementary Figure 1. Model fitting plots for MH release kinetics from formulation F-6 before and after storage for 6 months: (A) fresh, (B) on bench, and (C) at accelerated conditions. (i) Zero-order, (ii) First order, (iii) Higuchi square root of time, and (iv) Hixson and Crowell cube root.
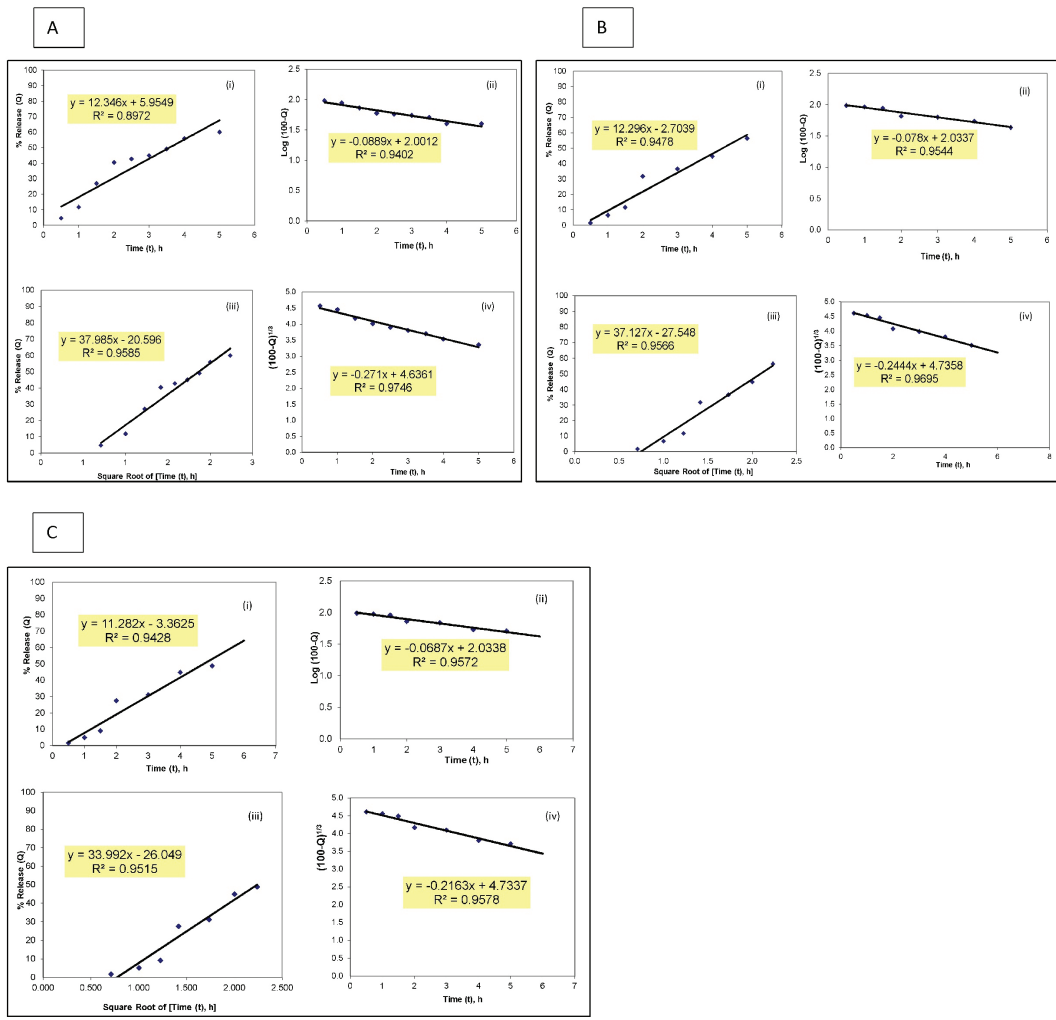

Supplementary Figure 2. Model fitting plots for MH release kinetics from formulation F-7 before and after storage for 6 months: (A) fresh, (B) on bench, and (C) at accelerated conditions. (i) Zero-order, (ii) First order, (iii) Higuchi square root of time, and (iv) Hixson and Crowell cube root. 
A

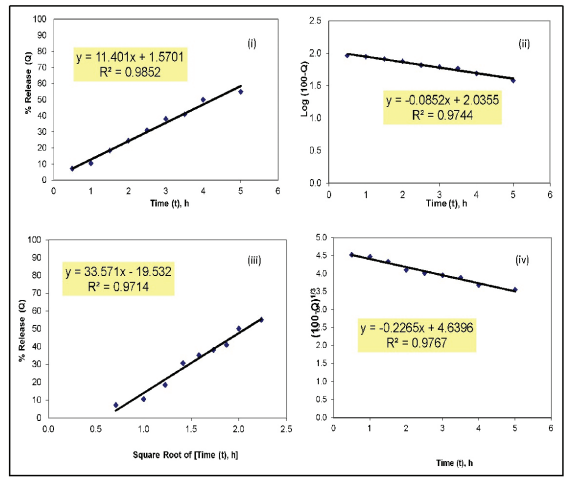

B

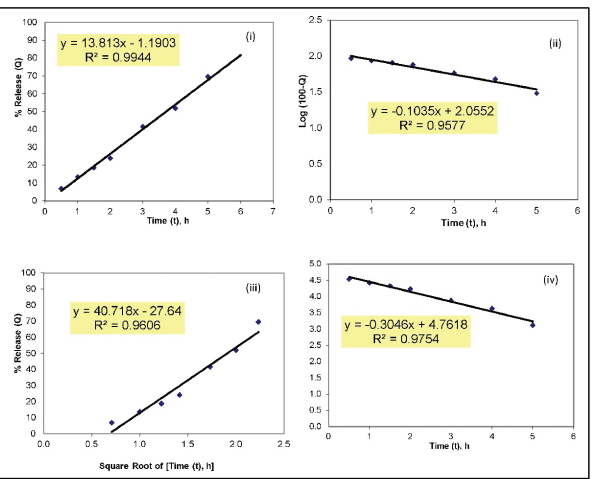

$\mathrm{C}$

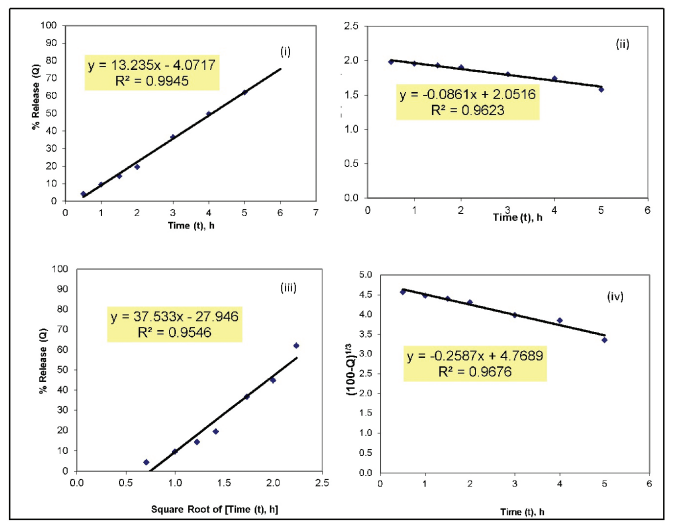

Supplementary Figure 3. Model fitting plots for MH release kinetics from formulation F- 8 before and after storage for 6 months: (A) fresh, (B) on bench, and (C) at accelerated conditions. (i) Zero-order, (ii) First order, (iii) Higuchi square root of time, and (iv) Hixson and Crowell cube root. 